\title{
TRENDS IN THE AREA OF MULTITASKING MACHINE TOOLS
}

\author{
POPPEOVA, V.; URICEK. J. \& BULEJ, V.
}

Abstract: This chapter is oriented on intensive development of turning machines in the last decades. Turning machine tools were qualitative changed to turning centre or multitasking machine with integrated operations for complex machining of workpieces on one machine. There is present increasing of parts complexity produced on turning centres during last years. Turning centres are currently manufactured by many producers, for examples Mori Seiki, DMG, Traub, Index etc. Multitasking machines represent the highest degree of development of machine tools for production complex shapes of workpieces with integration of chipless or unconventional (for example laser) technologies - there are listed Mori Seiki NT 100 and Mazak Integrex multitasking machines. Vertical turning machines are developed especially for HSC machining of flange parts. A lot of HSC machines were designed with parallel kinematic structures.

Key words: machine tools, turning centres, multitasking machine, vertical turning machines, parallel kinematic machines
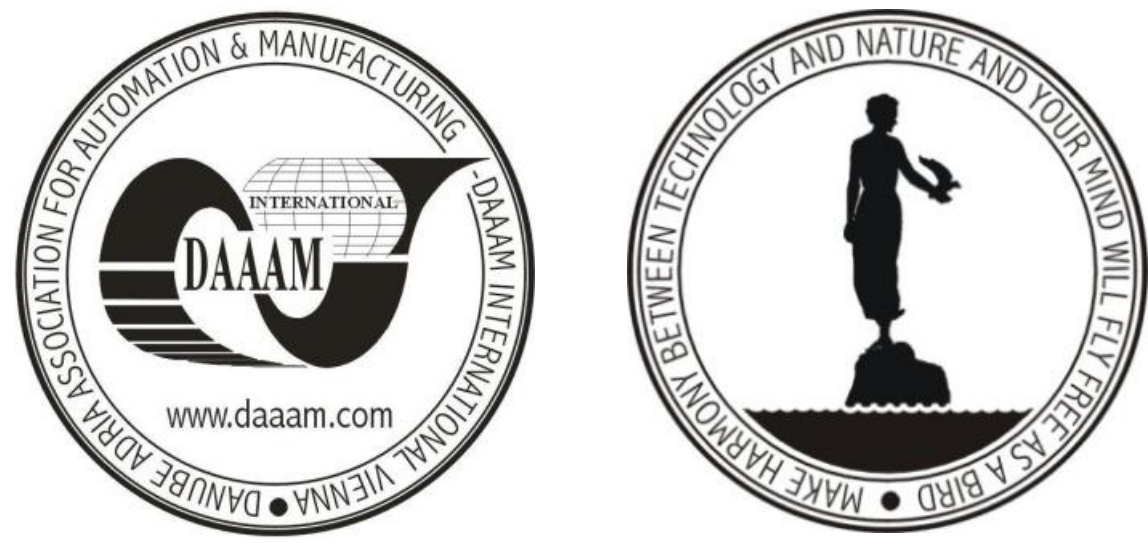

Authors' data: Assoc. Prof. Ing. Poppeova, V[iera]; PhD., Assoc. Prof. Ing. PhD. Uricek, J[uraj]; PhD. Ing. Bulej, V[ladimir], University of Zilina, 01026 Zilina, Slovakia, viera.poppeova@fstroj.uniza.sk, juraj.uricek@fstroj.uniza.sk, vladimir.bulej@fstroj.uniza.sk

This Publication has to be referred as: Poppeova, V[iera]; Uricek, J[uraj] \& Bulej, V[ladimir] (2011). Trends in the Area of Multitasking Machine Tools, Chapter 19 in DAAAM International Scientific Book 2011, pp. 227-242, B. Katalinic (Ed.), Published by DAAAM International, ISBN 978-3-901509-84-1, ISSN 1726-9687, Vienna, Austria

DOI: $10.2507 /$ daaam.scibook.2011.19 


\section{Introduction}

Numerically controlled (NC) lathes have been developed after three-axis machining centres in the fifties of last century. Compared machining centres were NC turning machines easier; they have only two programmed axes. Z-axis was defined as the axis parallel to the axis of the main turning spindle; $X$-axis is perpendicular to the axis $\mathrm{Z}$ and parallel to the radial movement of tools. Therefore both axes are horizontal, because the first $\mathrm{NC}$ lathes were based on the previously prevailing concept of conventional lathes with axial and radial tool movement in the horizontal plane. In terms of programming $\mathrm{Z}$-axis is designed to programming of turned length and the $\mathrm{X}$-axis to programming of turned work diameters.

In regard to the problems associated with complicated chip removal in the case horizontal positioning of tool were designed turning machines with vertical or slanted tools which provide secure chip removal. $X$-axis of such machinery is not horizontal but vertical or general, but always is perpendicular to the axis $\mathrm{Z}$ and parallel to the direction of radial displacement.

The turret is used as an optimal system for automatic tool changing at NC lathes by all manufacturers. It is a low - capacity magazine with ordered tools positioning, technologist must clearly determine tools configuration and location of all tools in the tray so that the total time of exchange of tools was minimal. Tool change time is determined by multiplying together the number of tool head slewing by exchanged between instruments and head rotation time of one step, which is at about half a second in this time.

Lathes of this type are produced also today.

At the EMO World Exhibition in Milan in 2009 we have seen several types of $\mathrm{NC}$ lathes, which were offered by manufacturers in today's challenging economic situation. Such lathes, equipped with only two controlled axes $\mathrm{X}$ and $\mathrm{Z}$, have the customer's address in particular the low cost and easy to use. Leading Japanese company exhibited new machines Mazak Quick Turn Smart Board in size 200 and 350. These machines have significantly simple rectangular design (Houša et al., 2010).

German company DMG (Dackel, Maho, Gildemeister) offers lathes CTX 310 and 510 in cheaper versions marked ECO. Machines have got rectangular shape covers, belt-driven spindle from an external drive unit (instead of coaxial drive in normal range CTX) and control system Sinumeric 810 D (instead of the 840 D).

\section{Operations integration on turning machines}

In terms of technological options are NC lathes, as well as conventional lathes, designed exclusively for the production of rotary surface - external and internal, mainly cylindrical, spur, bevel, shaping, etc. For the production of non-rotating surfaces that occur on the vast majority of shaft or flange parts, such as axial grooves, $\mathrm{n}$ - prisms, off - axial holes, helical grooves, shaped pockets and the like, had to be parts after turning machined on other machine tools - milling machines, drills. It is the source of a significant increase of production times, the need of the development 
of clamping tools and of course also the reason for the increase of inaccuracy due to multiple clamping of the workpiece. This production method is clearly inefficient and inaccurate.

Users and technologists have exercised an influence on manufacturers to produce manufacturing machines, enabling the production of parts with all surfaces rotary and non-rotary surfaces, i.e. machining complex parts in one machine.

A fundamental prerequisite to meeting this objective was the inclusion of axial tools - cutters, drills etc. to tool system of turning machines.

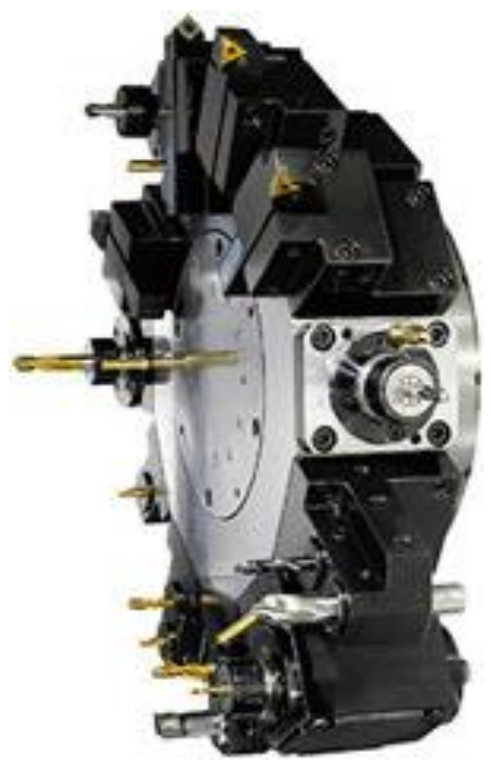

Fig. 1. Turret with turning and rotary tools

Addressing this issue has brought two new design concepts of turning machines for high productivity and accuracy:

1. Machines equipped with newly developed turrets, which provide work of turning tools, but also the work of the rotary axis tools (for example model BND-34C5 Miyano Machinery Inc. Company, Japan) (Fig. 1). This means that it must be ensured their rotating power drive with the relevant level of speed and power. This turret movement is programmed in three controlled linear axes $\mathrm{X}, \mathrm{Y}$ and Z. Machine tools with one or more such turrets are named: turning centres.

2. Turning machines with additional milling spindle (Fig. 2). This spindle has three coordinate linear axes and tilting around the $\mathrm{Y}$ axis - the rotation axis $\mathrm{B}$. These machine tools are known in literature as turn - milling centres, or multiprofessional, or multitechnological, or in general multitasking centres.

Turning machines with the above characteristics are designed for complex machining of parts on one machine. For example, machines with integrated operations Mazak Integrex manufacturer identifies with known slogan DONE IN ONE (do at once, on one machine).

Rotary axial tools operations are realized on the workpiece, which is clamped in the turning spindle (in first or in second spindle), it is necessary to manage the workpiece spindle rotation around $\mathrm{Z}$ axis - the axis $\mathrm{C}$. 


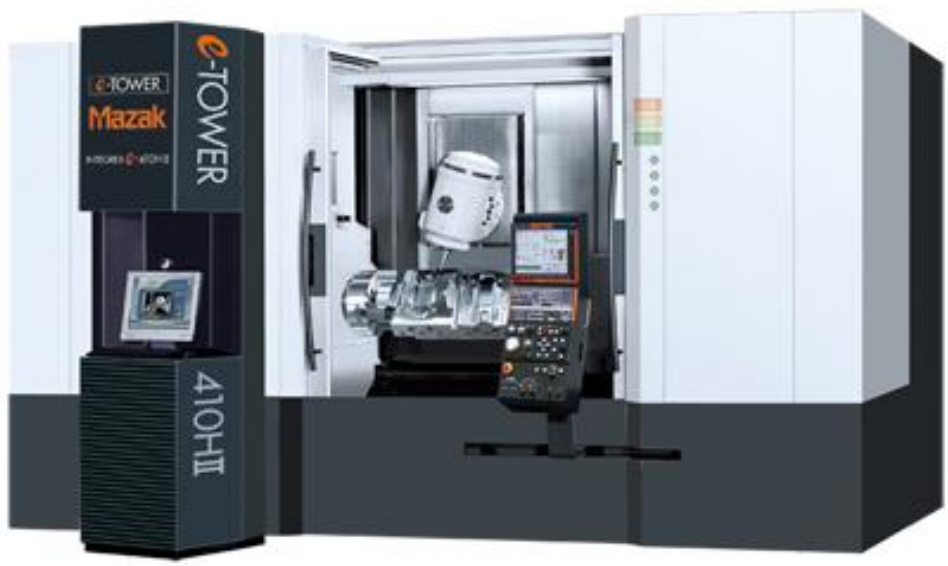

Fig. 2. Multitechnological centre Mazak Integrex e-410 HS (Japan) with milling spindle

This axis must perform the following functions:

1. Turning spindle fixation during rotary tools work - during milling, drilling etc.

2. Controlled rotation of the workpiece about a specified angle, for example 60 degrees in the manufacture of hexagon.

3. Controlled continuous rotation of workpiece, for example for milling of helical grooves.

Development of turning machines in the last decades has been intense and turning machine tools were qualitative changed to a new generation of machine tools with integrated operations for complex machining of workpiece on one machine.

Resolving of the deployment rotary tools and other technical adjustments has significantly changed working abilities of machines. Change in product assortment in recent years is demonstrated in Fig. 3 (Moriwaki, 2008).

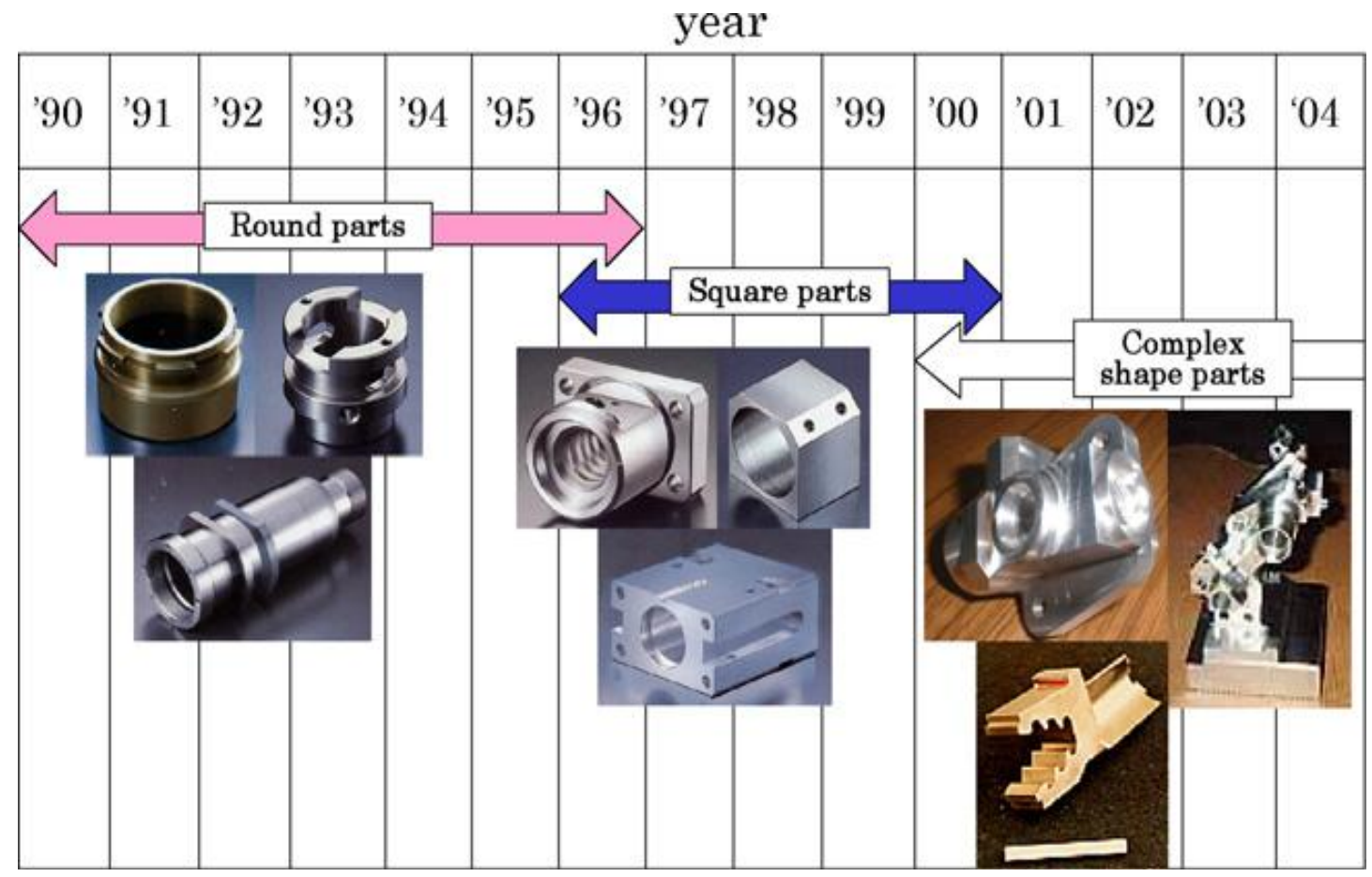

Fig. 3. Increasing of parts complexity produced on turning centres during last years 
The development of multitasking centres was associated with the operation integration of the various cutting professions (multiprofessional machines) or various manufacturing technologies (multitechnological machines).

Big pressure from the machine tools users was connected with hard cutting and finish grinding of external and internal surfaces. Realization of these operations without any manipulation on a one machine means a considerable simplification of the production process and strong shortening of the time of production of hardened parts.

EMAG Company used turning with the addition of $0.02 \mathrm{~mm}$ before grinding, so the minimum amount of material is removed during grinding. In cooperation with companies Reinecker and Karstens were made two lines of machines for this technology, named HDS (Hartdrehen und Schleifen; in German) (Housa et al., 2010).

Some machine producers have done also the integration of laser heat treatment (called dry), mainly surface hardening into the automatic machine cycle.

Machining of gearing, helical and worm surfaces are another group of integrated technological operations. Adding of axial workpiece support in the form of $\mathrm{NC}$ tailstock allows applied described type of technological operations also on shaft workpieces.

Adding of sub-spindle on twin - machines make it possible to shape machining of complex components from both sides, with using any of the above mentioned machining and chipless manufacturing operations, as well as checking operations on all workpiece surfaces.

\section{Turning centres}

Turning centres are designed for the overall efficiency production of shaped complicated parts on one machine tool. Turning centres are machines with one, two or three turrets, with main turning spindle and sub-spindle. They are currently manufactured by many producers.

Turning centre with one turret and one spindle has at least $\mathbf{4}$ controlled axes: $\mathrm{X}, \mathrm{Y}, \mathrm{Z}$ and $\mathrm{C}$.

Turning centres with two spindles and two turrets are designed for machining of complex shape parts from both sides on one machine tool. They have got usually 9 controlled axes:

1. First turret has 3 axes: $X_{1}, Y_{1}, Z_{1}$.

2. Second turret 3 axis: $X_{2}, Y_{2}, Z_{2}$.

3. Fixation and rotation of the first spindle: axis $\mathrm{C}_{1}$.

4. Fixation and rotation of the second spindle: axis $\mathrm{C}_{2}$.

5. Re-placing of the workpiece from first to second spindle: axis W.

These machines must have resolved automatic clamping of workpieces in both spindles and their moving from first to second spindle (W axis). This problem may have two solutions: 
1. In the tool magazine is placed the mechanical gripper to workpiece transfer from first to second spindle.

2. One spindle (usually sub-spindle) is designed like sliding. After workpiece machining from one side in first spindle is moved sliding spindle toward the workpiece on the coordinate designated by position of further clamping surface of the machined part. Chuck in the sliding spindle clamps the workpiece on this surface and the main spindle chuck releases the part. Sliding spindle with part is moved to working position, where is completes machining of the part from the other side.

In Fig. 4 is presented an example of turning centre with two spindles and two turrets (Moriwaki, 2008). Turning centre has got total eight controlled axes: the first turret on upper carriage has got 3 controlled axes: $\mathrm{X}_{1}, \mathrm{Y}, \mathrm{Z}_{1}$, in it can be placed rotary and static tools. The second turret has two axes: $X_{2}, Z_{2}$ (turret is intended only for turning static tools, has no mechanism for the drive of rotary tools and has not $\mathrm{Y}$ axis). The first spindle has got driven rotational axis $C_{1}$ and second spindle $C_{2}$ axis. The eighth axis, which is not in the picture drawn, is the axis named $\mathrm{W}_{2}$ (linear movement of the second reconfigurable spindle).

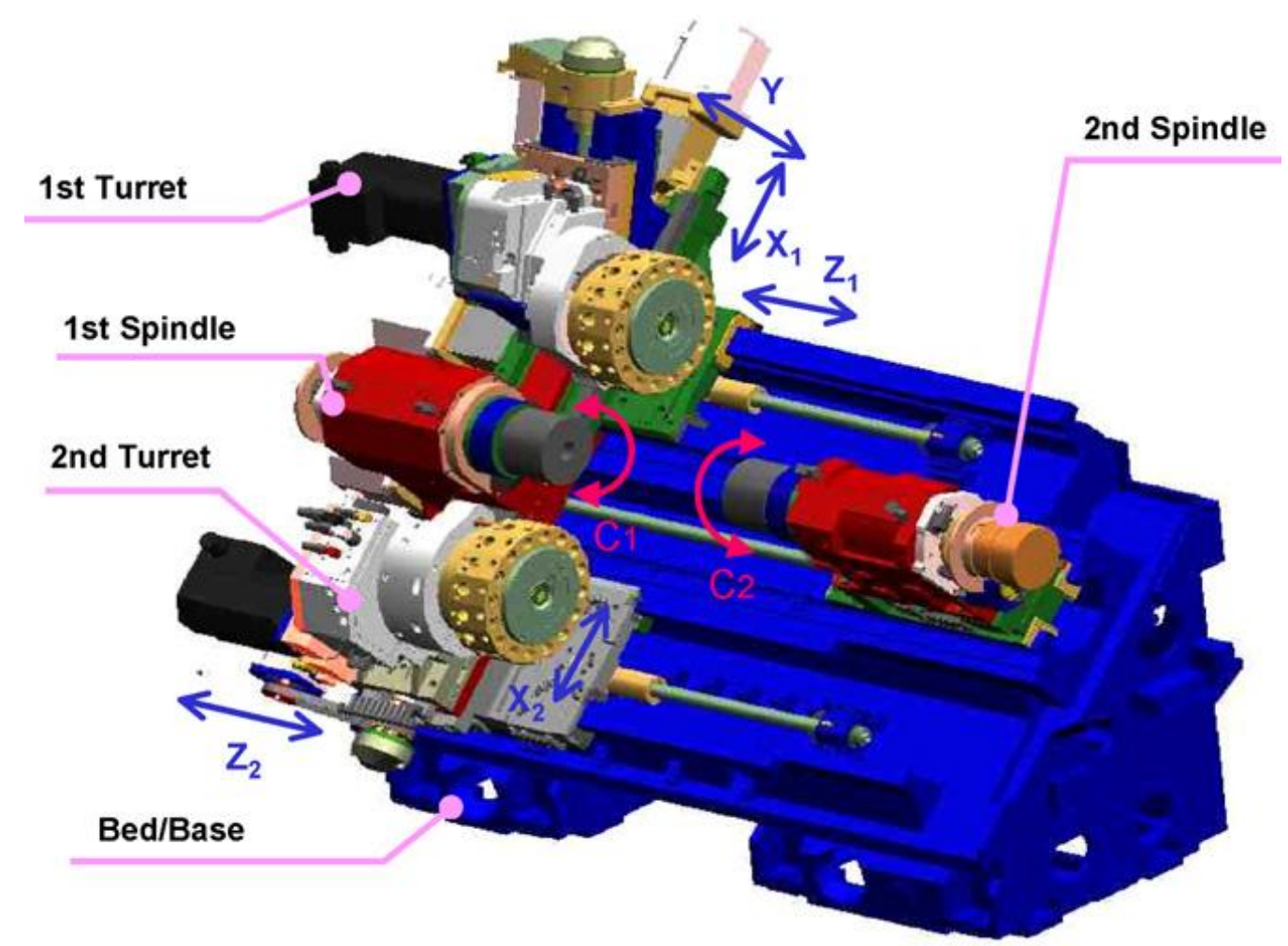

Fig. 4. Example of configuration of turning centre with two spindles and two turrets with 8 controlled axes

The modular structure of this machines category allows manufacture the machine tool exactly as needed. Individual variants differ mainly by the number and arrangement of turrets and by the number of motion axes of turrets. Parameters of the second spindle are usually the same as for the main turning spindle, so there can be independently machined two workpieces. 
Turrets are crucial elements that determine the production potential of this machine tools type. Direct drives with rotary annular engines are beginning to promote as compact and powerful solution for rotary driven tools in turrets. Pioneer in this field is the company Mori Seiki, which annular motor is integrated in the turret called DDM - Direct Drive Motor.

A similar solution with an integrated annular engine is also used on the heads Sauter, which are mounted on machine DMG CTX Alpha and Beta. Direct drive can propel tool with maximum revolutions up to $6,000 \mathrm{~min}^{-1}$, power $5.5 \mathrm{~kW}$ and torque $40 \mathrm{Nm}$. Company Sauter has already developed a direct drive of rotary tools with the maximum revolutions of $12,000 \mathrm{~min}^{-1}$ and $13 \mathrm{~kW}$ power, the turret with direct drive for rotation of heads and continuous control of position (Houša et al., 2010).

The production possibilities of turning centres with multi-turrets are at machine tools exhibition presented with plenty of complex shape workpieces with a large share of off-axis drilling and milling operations.

Well equipped turning centres in this regard are struggling to cope to multifunction turning centres. Growing parameters of rotary tools drive allow fully effective milling. For example, Mori Seiki company states that the NZ series machines can be equipped with milling heads up to a diameter of $80 \mathrm{~mm}$. Technological capabilities of the machine can be extended with special tools in turrets. At Doosan Puma machine TT1800SY is used auxiliary equipment for gear milling with using gear hobbing cutter.

The machine Bigla B765 Y3 uses additional slotting tool from company Mario Pinto, which can make slot with length of $5 \mathrm{~mm}$ and depth $3.5 \mathrm{~mm}$ in the hardened and tempered steel $38 \mathrm{NCD} 4$ in 6.6 seconds. The device is manufactured with a stroke of $35 \mathrm{~mm}$ and $65 \mathrm{~mm}$.

The company DMG (Germany) is significant manufacturer of turning centres, in the machines line Sprint linear offers one turning centre with 12 controlled axes Sprint 50/12 linear, three centres with 10 controlled axes and 4 types with 8 axes.

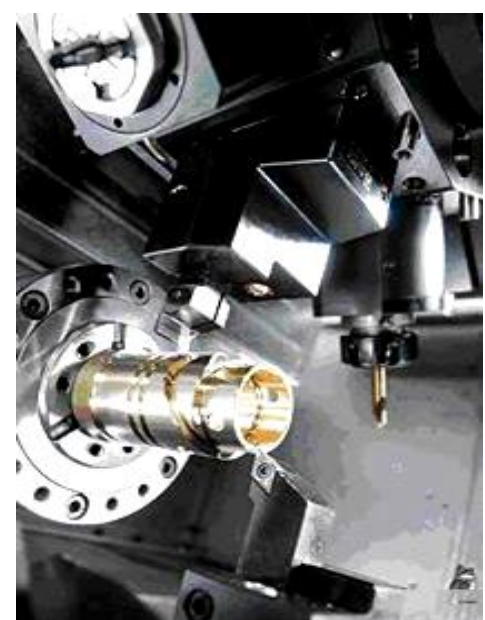

a)

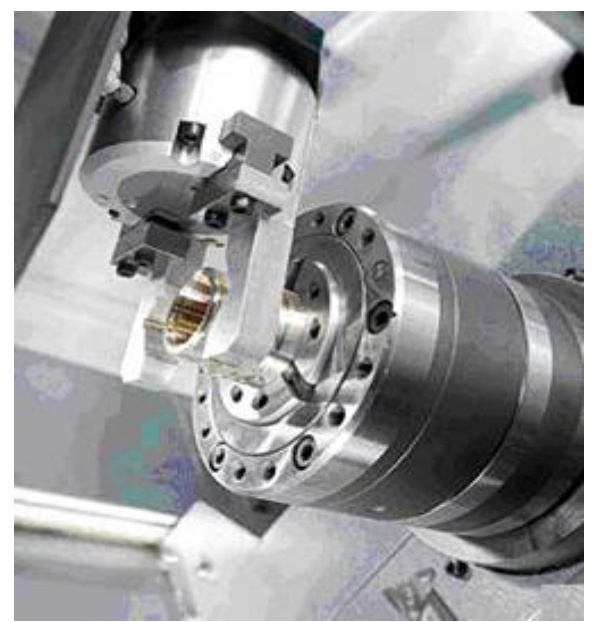

b)

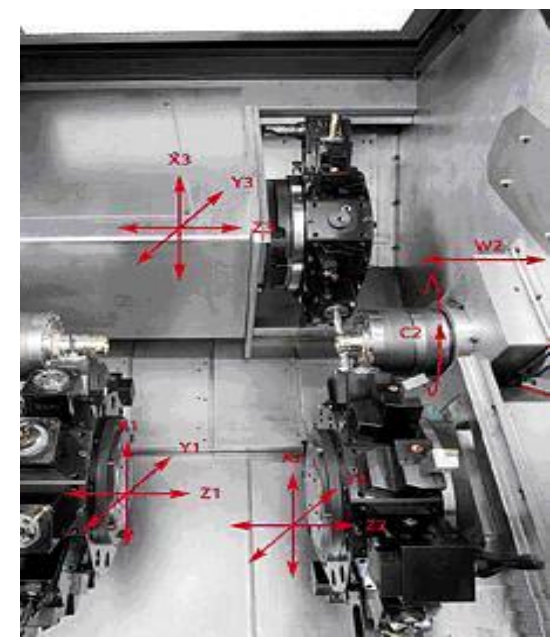

c)

Fig. 5. Complex machining of complicated workpieces at the centre DMG SPRINT 50 linear with static and rotation tools (a), the gripper for the automatic exchange of workpieces (b), work space and coordinate systems - simultaneous machining of two workpieces with three tools (c) 
Poppeova, V.; Uricek. J. \& Bulej, V.: Trends in the Area of Multitasking Machine ...

In Fig. 5 (www.dmg.sk, 2011) are presented details of the work of turning centres DMG SPRINT 50 linear. The centre has three turrets with static and rotary tools (3 time 3 axes) and together with the spindles axes C1, C2 and W2 has totally 12 controlled axes. Used are linear feed actuators, feed speed $40 \mathrm{~m} . \mathrm{min}^{-1}$ and acceleration $1 \mathrm{~g}$ ( $\mathrm{g}$ - acceleration of gravity).

In Fig. 5c and 6 are shown two examples of turning centres (DMG and INDEX), with three turrets - there we can see simultaneous machining of two workpieces placed in two independent spindles with three tools (http://www.indexwerke.de/de/deutsch/521_DEU_HTML.htm (2011).

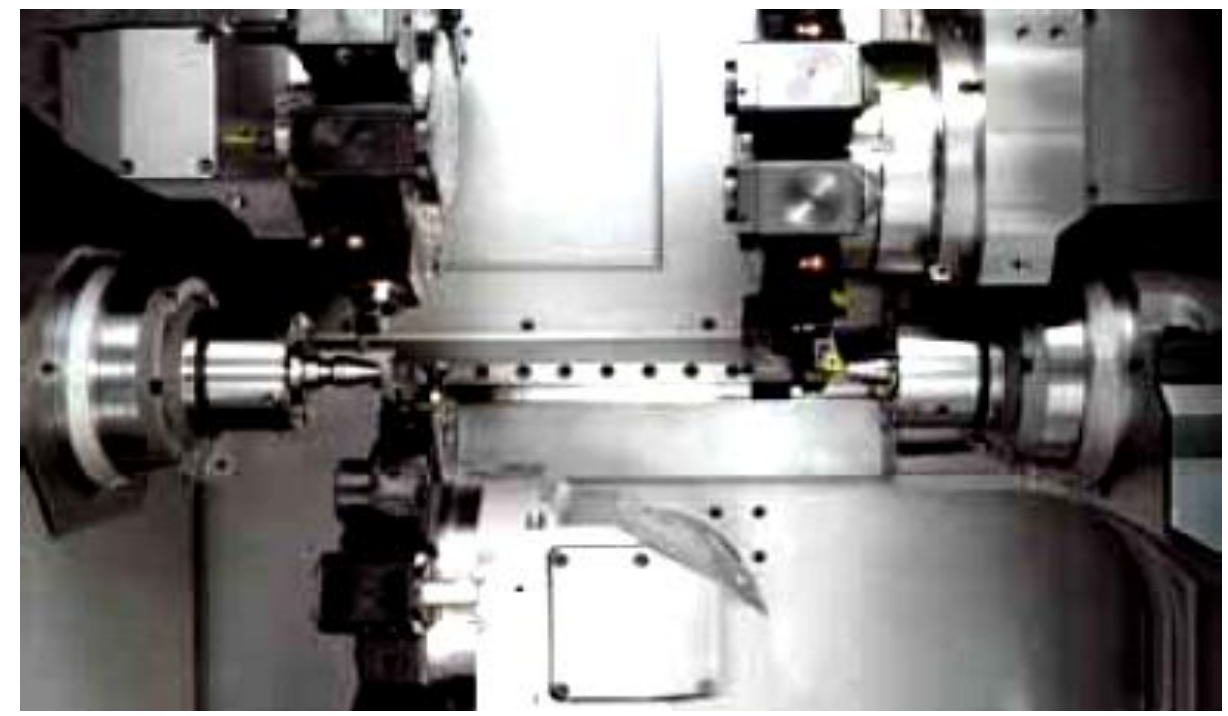

Fig. 6. Twin-spindle turning centre INDEX C 100

The turning centre DMG CTX beta 800 linear (www.dmg.sk, 2011) provides additional performance in power, torque and precision. Idle times are reduced to a minimum because of the highly dynamic linear drive in the $\mathrm{X}$-axis which makes rapid traverses of up to $60 \mathrm{~m} \cdot \mathrm{min}^{-1}$ and accelerations of up to $1 \mathrm{~g}$ possible. Larger workspace is achieved through targeted structural standards without having to increase the space requirements of the machines. This additional space is converted again to an increased functionality of form that provides larger machining diameters as well as improved chip removal.

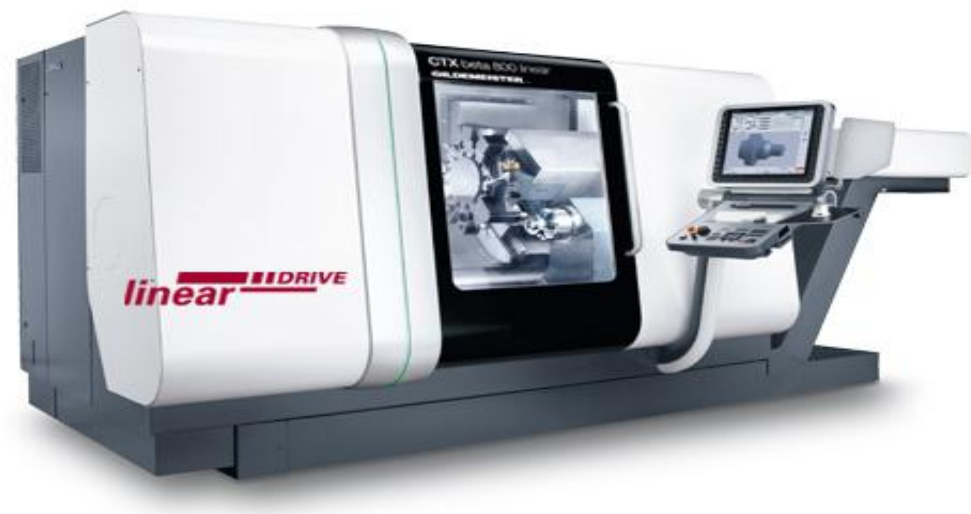

Fig. 7. Turning centre DMG CTX beta 800 linear 


\section{Multitasking Machines}

Multitasking machines represent the highest degree of development of turning machines for production of complex shapes workpieces in one machine. In the literature, we have to deal it with names multiprofessional or multitechnological or multitasking machines in general.

The concept of multiprofessional machines includes the machines, which combine different types of the machining technology operations - professions. Here appertain the cutting operations realized with static and rotary tools - turning, milling, drilling, boring, thread machining, milling with hobbing cutter and machining of the grooves. Already are produced centres with the possibility of integration abrasive operations, especially grinding.

The term the multitechnological machines means machines with integration of machining with other production technologies. It may be a chipless material removal with chemical, electrochemical and electroerosive processes or with high-energy beams, such as laser, electron and plasma. There are also the additional ancillary production technologies - e.g. heat treatment of metal surfaces, laser welding of parts, induction heating, balancing rotating masses or checking measures.

The most important part of multitasking centres is the additional spindle (called milling spindle), which has four controlled axes - three driven linear axes $X$, $\mathrm{Y}, \mathrm{Z}$ and rotational axis B - spindle rotation about the axis $\mathrm{Y}$ (Fig. 2 and 8).

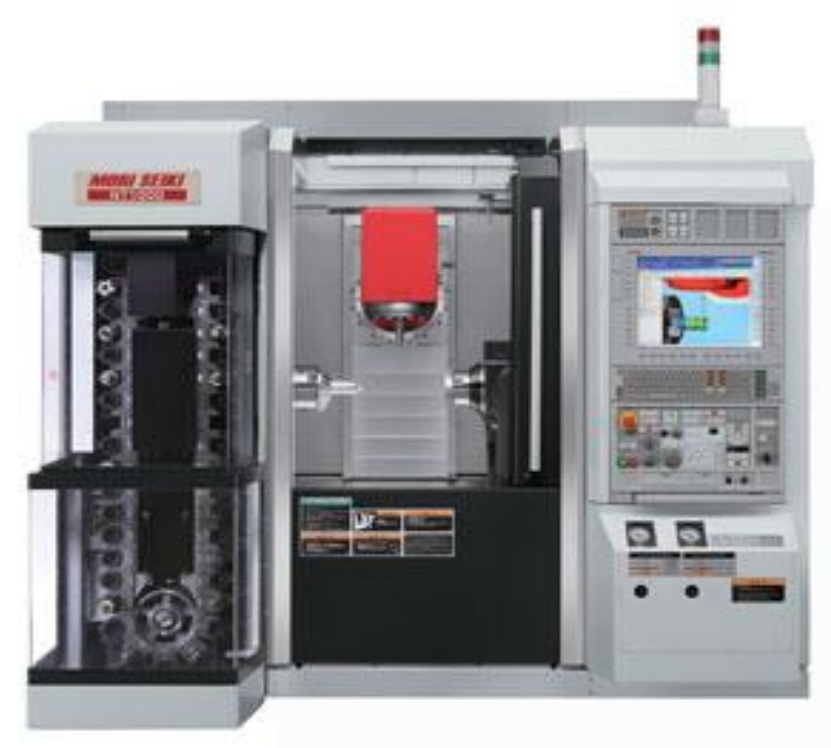

Fig. 8. Multitasking centre Mori Seiki NT 1000

Mori Seiki Company (Japan) unveiled at EMO 2009 exhibition the machine concept labelled NT1000 (Fig. 8) (http://www.moriseiki.com/index.html, 2011). This is a very complicated machine that allows connect an automatic bar feeder or work from blanks. Machine is equipped with a universal unit, which allows machining of long pieces and postponing of the final piece in the output tray. Basic configuration of the machine can be extended with the right or left lower turret. Vertical chain tools magazine is located on the left side of machine. 
Poppeova, V.; Uricek. J. \& Bulej, V.: Trends in the Area of Multitasking Machine ...

In the additional (milling) spindle are placed tools through a system of automatic tool changing. It includes the high capacitive chain tools magazine, located at the side (Mori Seiki) or back of the machine (MAZAK) (Fig. 8).

At these centres is used for the automatic transfer of workpiece a sliding lathe spindle or gripper (Fig. 5b), which is located in a chain magazine as one of the instruments. In the tool magazine can be placed also static turning tools that work in the fixed milling spindle. There is often included in the tool magazine the measuring probe and other important devices.

The workpiece is clamped to the lathe spindle, it can be machined with turning tools in fixed milling spindle or in the turrets, or can be realized five axes milling, or the work of several instruments combination.

They are universal productive machines, which show the typical design elements depending on the size of the machine.

Among the most known machines of this concept belong series of multitasking centres Mazak Integrex, for example in the Fig. 2 is shown a centre Mazak Integrex e-410 HS, which is intended for the production of complex parts in large scale.

The technological capabilities of the machine Mazak Integrex $200 \mathrm{Y}$ are shown in Fig. 9, 10 and 11.

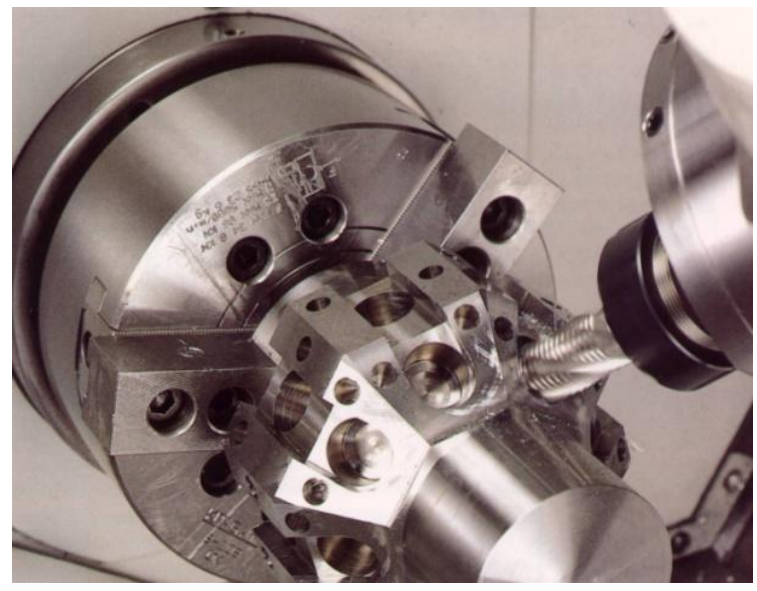

a)

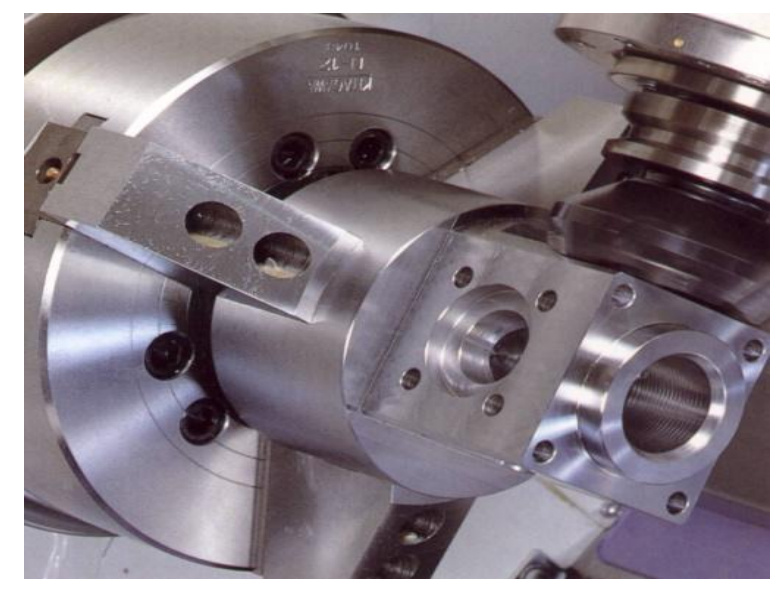

b)

Fig. 9. Milling on the centre Mazak Integrex $200 \mathrm{Y}$ (a), the thread cutting into offaxis holes (b)

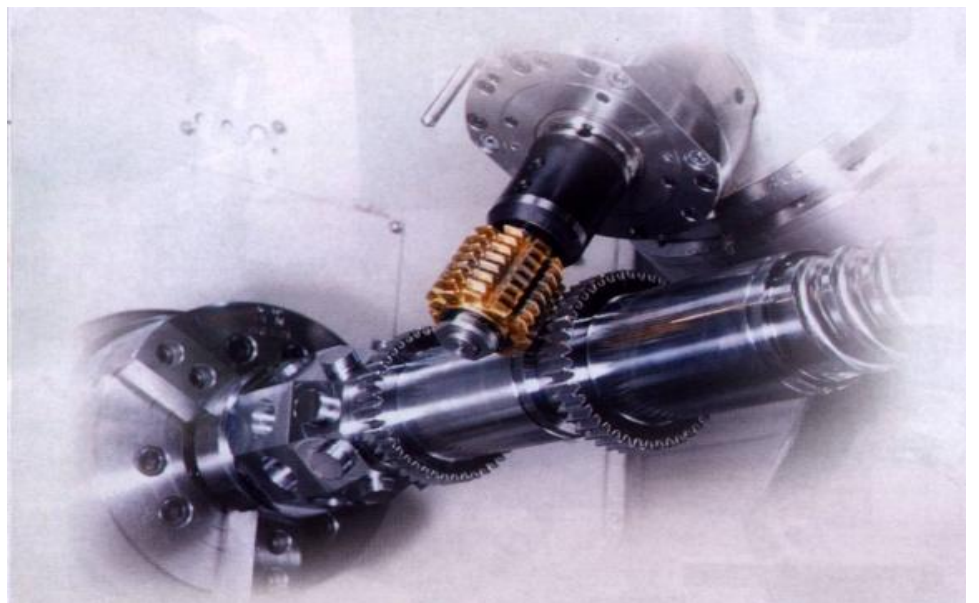

Fig. 10. Gear milling with the hobbing cutter on the centre Mazak Integrex $200 \mathrm{Y}$ 


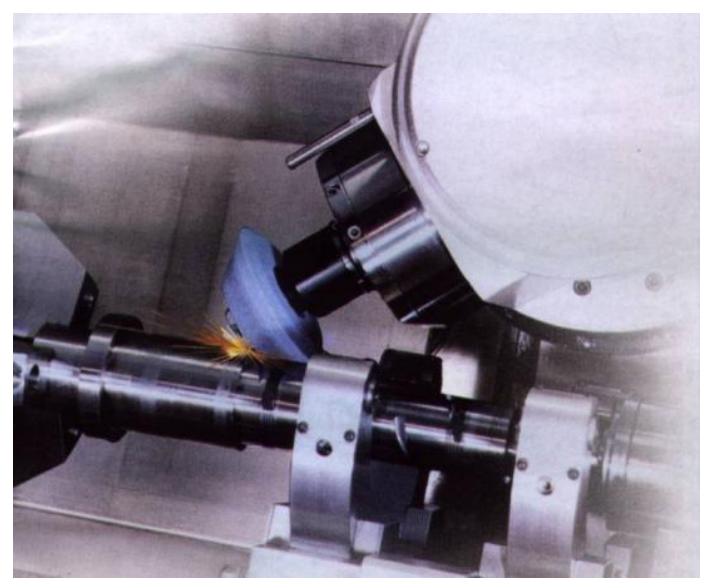

a)

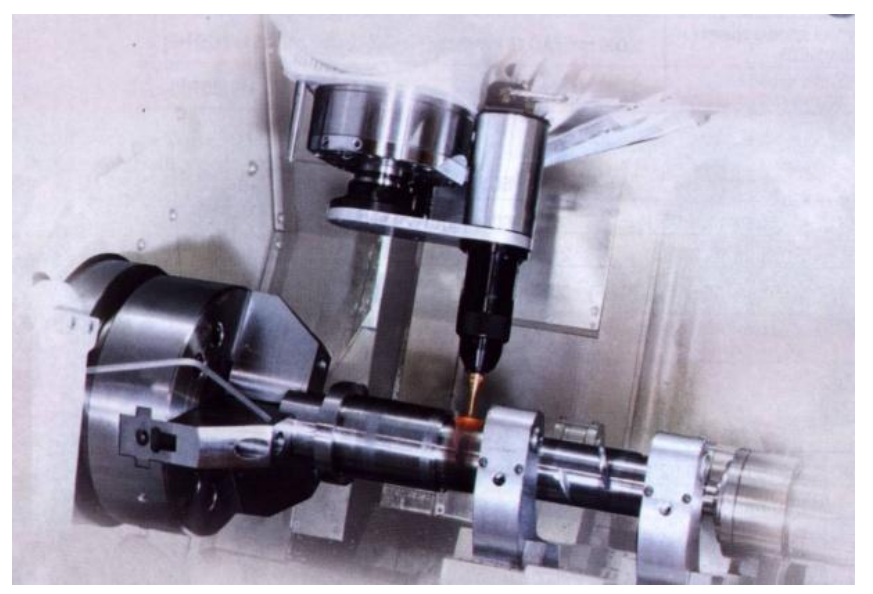

b)

Fig. 11. Grinding on the centre Mazak Integrex $200 \mathrm{Y}$ (a), surface hardening with laser beam (b)

Smaller multifunction machines with similar concept were exhibited at last EMO exhibition, for example from companies Bumotec, Willemin Macodel or Realmeca. In terms of equipment design are interesting machines Bumotec S-191, which have direct power drives with linear or ring-shaped engines for all axes. Exhibited machines were presented by complex workpieces, which show full working capacity of machines, for example specimens of dental or body joint implants. They are the parts with complicated shaped surfaces, made from special titanium alloys. Extreme demands are posed on accuracy and surface quality (Housa et al., 2010).

Larger multi-centers are always equipped with lathe counter-spindle, which has the same parameters as the main spindle. Almost all machines in this category were also equipped with the lower turret, which allows the simultaneous cutting with two powerful tools in cooperation with the tool clamped in the milling spindle.

Company DMG in this category (http://cn.dmg.com/us,turning,ctx) produces machines Gildemeister CTX series named CTX beta 1250 TC, gamma 1250 TC and gamma 2000 TC. Multitasking machine DMG CTX gamma 1250 TC is equipped with linear motor in the axis $\mathrm{X}$, can be also equipped with a chain magazine with capacity up to 120 tools. Machines in this category enable besides turning and 5-axis milling operations also the boring with long boring tools that are able to automatically exchange. This makes possible special tool magazine. The machine is equipped also with a lower turret.

Company Okuma presented for new centre Multus. The Okuma Multus-B200 is a general purpose multi-function machine that is designed to reduce set up time by virtually eliminating repetitive clamping to improve accuracy and keep non-cutting time to a minimum. Collision Avoidance System software combined with Okuma's THINC-OSP Control can run the entire machining simulation and catch potential collisions before they create scrap. Thermal-Friendly Construction assures high accuracy, even in the most complex applications. Options include the $\mathrm{W}$ version with sub-spindle, which is designed to hand the part from one spindle to the other to complete milling and turning operations without changing the part. Multus machine 
Poppeova, V.; Uricek. J. \& Bulej, V.: Trends in the Area of Multitasking Machine ...

functionality can be extended with special set for workpiece balancing, in which the axis $\mathrm{C}$ functions as a balancing device and determine where have to be drilled balancing holes.

\section{Vertical turning centres and multitasking machines}

Vertical turning machines are developed in several companies especially for flange parts HSC machining. They have the upper inverse turning spindle with a vertical axis. Workpieces are clamped in this vertical upper spindle, in upside down position, (i.e. opposite to the carousels). Company Index (Germany) produces the vertical lathes with several types of spindles with excellent chip removing without the cutting fluids using.

Example of vertical machine with two spindles for complex machining of complicated shapes on both sides of flange parts is vertical turning centre MAG Hüller Hille DVT 300. This machine is equipped with two vertical spindles and two turrets (Fig. 12). To the left side is located the entrance to the machine with stepconveyor, the upper left spindle with a vertical axis is able to horizontally traverse. This spindle has also a pick-up system for workpieces manipulation; it captures the blanks from the conveyor and returns into the work position (http://www.magias.com/en/mag/products-services/turning/vertical-turning-centers/dvt.html, 2011).

The workpiece is machined from below side (the over head turning) with tools clamped in the left turret. There can be applied static tools or different types of rotary tools, which can create on the workpiece the planar and general surfaces, straight or helical grooves and general holes.

After part machining from one side is upper spindle with workpiece shifted to the right lower stable spindle. Machining of parts from the other side is realized with the tools placed in the right turret.

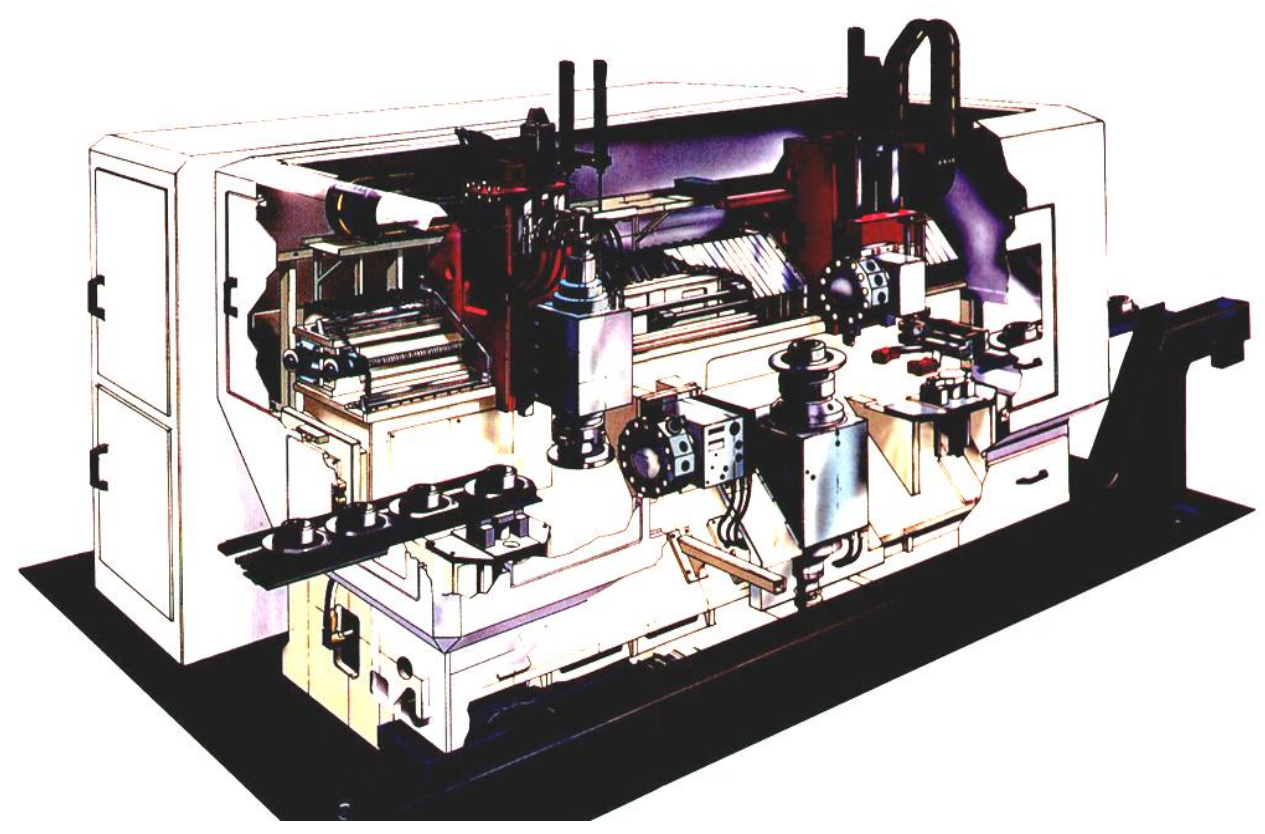

Fig. 12. Twin-spindle vertical turning centre DVT 300 (company MAG Hüller Hille, Germany) 
Manipulator removes finished workpieces from stable spindle to the output conveyor (on the right side).

Centre provides complex technological circle; includes transport and handling subsystem and machine conception may be considered a flexible manufacturing system of the $4^{\text {th }}$ generation.

\section{Machines with Parallel Kinematic Structure}

High speed cutting and automation of manufacturing lines are presenting mainstream in current development of machine tools, robotics and automated workstations. Raising the speed of working cycle increases the pressure and requirements on construction and configuration of working cells, equally also statically and dynamically stiffness, temperature stability and precision. Reduction mass of moving machine units on minimum is necessary to achieve high dynamic properties of the machine. This request is complete by machines with parallel kinematic structure. Complicated control of kinematic mechanism is the heavy obstruction for putting machines with parallel conception to the machine industry. Request for qualitative software and hardware equipment of the control system is necessary condition for effective process control of those structures. Progress of electrical engineering and information technologies brought the possibility to develop it on various universities and apply it to the industrial praxis. This architecture has been applied in more areas of industry and thereby increased the production process successfully.

The development of PKS is short-run compared with long-run machinery development of serial kinematic structure. Whereupon it is possible to expect, that in the future will arise more and more projects supporting PKS research.

Parallel kinematic structures have recently attracted attention as machine tools and robots because of their conceptual potentials in high motion dynamics and accuracy combined with high structural rigidity due to their closed kinematics loops.

Parallel kinematic structure is a closed-loop mechanism in which the endeffector is connected to the base by independent kinematic chains. Each link is driven by unique prismatic or rotary actuator.

Inverse kinematic analyse is used in parallel kinematic structures design. Analyse makes possible to determine important mechanism properties, as are position, speed and acceleration of rotary or linear mechanism parts as well as tool centre point.

Movement of tool centre point is realized by changing of length and space orientation of all mechanism legs. Realization most simply movements needs coordinate cooperation all legs too.

Calculated length values of mechanism legs are operated in control system and are sent to power unit in periodical time interval. 
Poppeova, V.; Uricek. J. \& Bulej, V.: Trends in the Area of Multitasking Machine ...

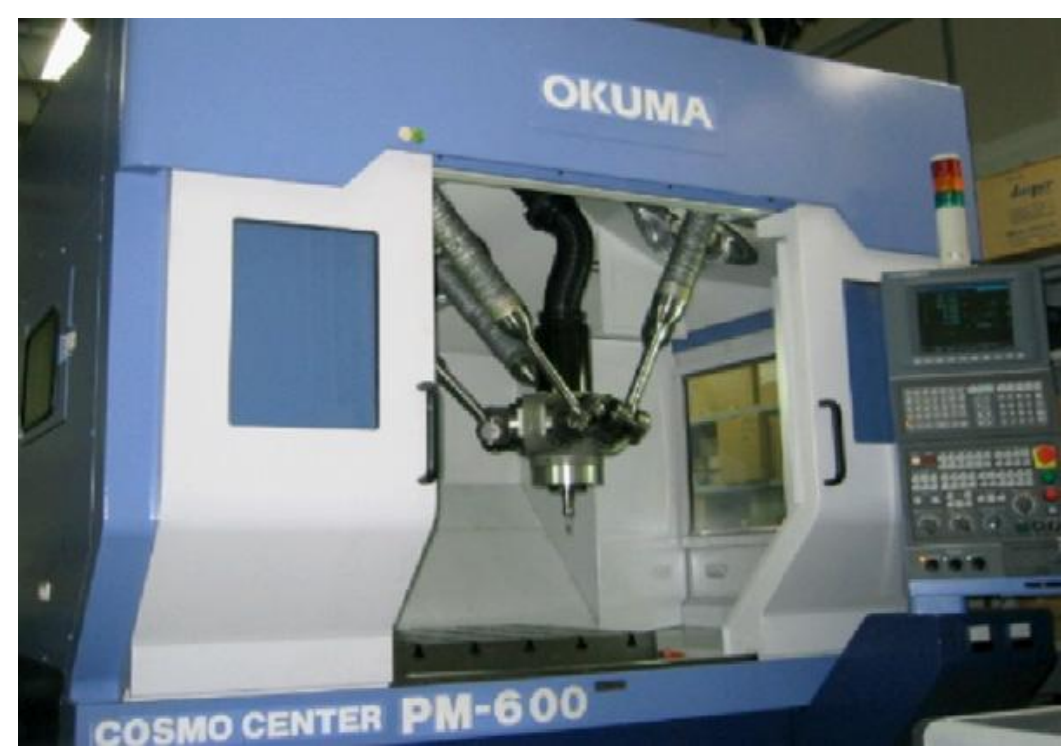

Fig. 13. Parallel kinematic machine OKUMA Cosmos Centre PM 600

Most machines with parallel kinematic structure have from two to six degrees of freedom of motion. An example of a commercial parallel kinematic machine (PKM) OKUMA Cosmos Center PM 600 is shown in Fig. 13 http://www.okuma.com/products/machines/vmc/pm600v/(2011). The linear and rotary motions of $\mathrm{X}, \mathrm{Y}, \mathrm{Z}, \mathrm{A}, \mathrm{B}$ and $\mathrm{C}$ in the Cartesian coordinate system are realized by controlling the lengths of six struts L1- L6 in this case.

Some PKM are based on combinations of parallel and serial kinematic structures - hybrid structures to increase the flexibility of motions. The design features and the specific characteristics of PKM are reported by Weck and Stainmer in the 2002 CIRP Keynote paper, and therefore they are not repeated here (Weck \& Staimer, 2002).

At our university was built one hexapod and one trivariant kinematic structures prototype used for testing, functional verification, for education and training.

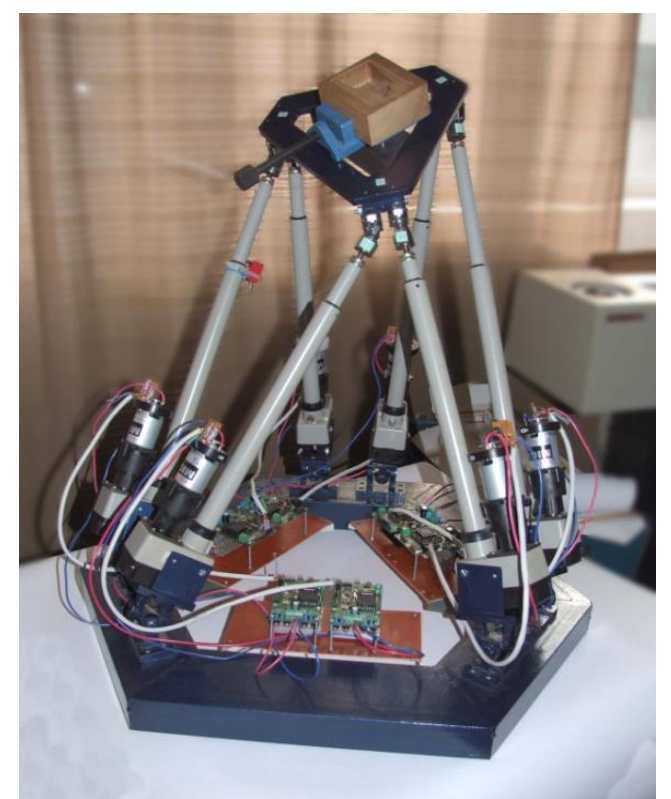

Fig. 14. Hexapod kinematic structure (University of Zilina) 
Hexapod - the mechanical construction consists of base, platform and six identical linear actuators with system screw-nut. For the connection to the base and also to the platform are used the cardan joints. In Fig. 14 is shown the hexapod, which was built at University of Zilina (Poppeova et al., 2008).

Trivariant - is based on the hybrid kinematic structure (Fig. 15). The basic part of machine is the positioning mechanism with parallel kinematic structure, which is very similar to the classic tripod (Poppeova at al., 2009). The whole device has 5 degree of freedom (DOF), which is enough for the 5D machining. If the mechanism is used like a manipulator, we can add one more axis to the serial extension. Then this machine work with 6 DOF.

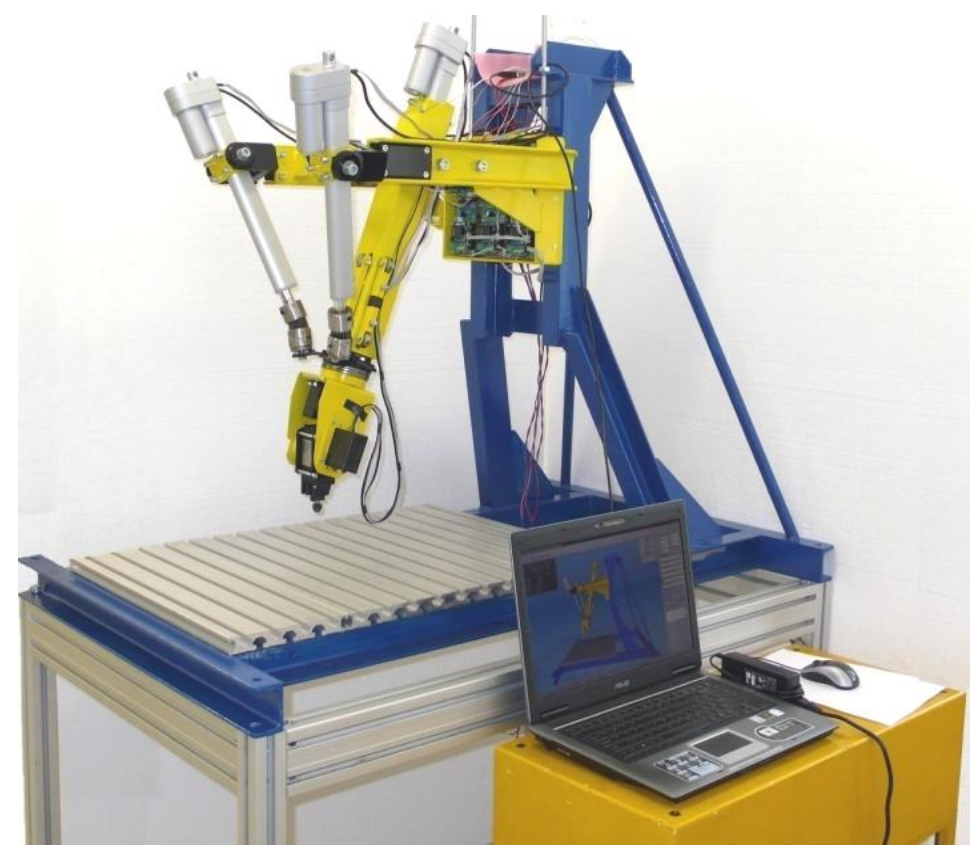

Fig. 15. Trivariant hybrid kinematic structure (University of Zilina)

There were developed mechanical subsystems for both of parallel mechanisms, simulation software, power and sensors subsystems and control systems based on standard PC. We have carried out also the inverse kinematic analysis for each mechanism.

In this time are designing the application of these structures for parallel kinematic machines prototypes based on hexapod and also on trivariant at University of Zilina.

\section{Conclusions}

The main requirements for the current production machinery are - to ensure full production, its high productivity and quality. Suppliers of machines confirm the demand for sophisticated production solutions with high manufacturing productivity despite the current difficult economic situation.

Producers of the turning machines try to achieve the desired complexity of machines with multiple turrets and using modular design. 
Poppeova, V.; Uricek. J. \& Bulej, V.: Trends in the Area of Multitasking Machine ...

Machine tools can be produced according to specific customer requirements because exists a large number of kinematic configurations.

For flexible production of complex parts are offered the multitasking centres which integrate several technologies.

Current machine tools can be classified as the advanced mechatronic devices.

Recent development of multitasking centres can be regarded as one of the ways to develop so-called universal machining centres - the universal production means for machining of complex shapes of parts which are no longer categorized as rotary and no-rotary as yet.

\section{Acknowledgement}

The article was created with the support of the Slovak Scientific Grant Agency VEGA and at project 1/0207/10.

\section{References}

Housa, J. et al. (2010). Machine tools and technology on EMO Milano 2009, SpOS and VCSVTT, CVUT Praha

Moriwaki, T. (2008). Multi-functional machine tool, CIRP Annals - Manufacturing Technology 57, p. 736-749

Poppeova, V., Cubonova, N., Uricek, J. \& Kumicakova, D., (2002). Automation of mechanical production, EDIS ZU Zilina

Poppeova, V.; Uricek, J.; Zahoransky, R.; Rejda, R.; Bulej, V. \& Durica, J., (2008). The Development of Hexapod Kinematic Structure, p. 1133- 1134, Annals of DAAAM for 2008 \& Proceedings of the 19th International DAAAM Symposium, ISBN 978-3-901509-68-1, ISSN 1726-9679, pp 567, Editor B.

Katalinic, Published by DAAAM International, Vienna, Austria

Poppeova, V., Uricek, J., Bulej, V. \& Sindler P., (2009). The Development of

Mechanism with Hybrid Kinematic Structure Prototype. In: Journal of Machine

Engineering, Knowledge Based Manufacturing Machines Operation, Vol. 9, No. 3, 2009, Ed. J. Jedrzejewski. Editorial Institution of Wroclaw Board of Scientific Technical Societies Federation NOT, Wroclaw 2009, Poland, p. 102 - 109, ISSN 1895-7595

Vrabec, M., (2002). The problematic of numerical programmed machines programming, CVUT Praha

Weck M. \& Staimer D (2002). Parallel Kinematic Machines Tools-Current State and Future Potentials, Annals of the CIRP 51(2), p. 671-684

*** (2011) www.dmg.sk

*** (2011) http://www.index-werke.de/de/deutsch/521_DEU_HTML.htm

*** (2011) http://www.moriseiki.com/index.html

*** (2011) http://www.mag-ias.com/en/mag/products-services/turning/verticalturning-centers/dvt.html

*** (2011) http://cn.dmg.com/us.turning.ctx

*** (2011) http://www.okuma.com/products/machines/vmc/pm600v/(2011) 